\title{
Corela
}

Cognition, représentation, langage

HS-23 | 2017

The Genesis and Dynamics of Spatial Adpositions

\section{Three basic prepositions in French and in English : a comparison}

\section{Claude Vandeloise}

\section{(2) OpenEdition}

1 Journals

\section{Electronic version}

URL: https://journals.openedition.org/corela/5033

DOI: $10.4000 /$ corela.5033

ISSN: 1638-573X

\section{Publisher}

Cercle linguistique du Centre et de I'Ouest - CerLICO

\section{Electronic reference}

Claude Vandeloise, "Three basic prepositions in French and in English : a comparison", Corela [Online], HS-23 | 2017, Online since 14 November 2017, connection on 21 September 2021. URL: http:// journals.openedition.org/corela/5033 ; DOI: https://doi.org/10.4000/corela.5033

This text was automatically generated on 21 September 2021

\section{(c) (i) (2)(2)}

Corela - cognition, représentation, langage est mis à disposition selon les termes de la licence Creative Commons Attribution - Pas d'Utilisation Commerciale - Partage dans les Mêmes Conditions 4.0 International. 


\title{
Three basic prepositions in French and in English : a comparison
}

\author{
Claude Vandeloise
}

1 A strong parallelism is often established between the French prepositions à, sur and dans and the English prepositions at, on and in. I call them basic because they are among the most frequently used spatial prepositions and, particularly for on and in, among the first prepositions learned by children. The geometric analyses of these prepositions (Gougenheim 1959, H. Clark 1973), consider $\grave{a}$ and at as zero-dimensional (or adimensional) prepositions, sur and on as one-dimensional or bi-dimensional prepositions and dans and in as tri-dimensional prepositions. The correspondence between the basic spatial prepositions in French and in English appears in the following examples :
(1) La voiture est au carrefour
(2) The car is at the crossroads
(3) Le crayon est sur la table
(4) The pencil is on the table
(5) Le couteau est dans le tiroir
(6) The knife is in the drawer

2 There are however important discrepancies between these prepositions, illustrated by sentences (7)-(10) :

(7) L'enfant est à Rome

(8) The child is in Rome

(9) L'enfant va à Rome

(10) The child goes to Rome

3 Whereas in sentences (7) and (9), French uses $a$ for the actual position of a target as well as for its prospective position, English draws on the preposition to to introduce the prospective position of the child in sentence (10). Furthermore, as illustrated by sentence (8), English utilizes in in front of geographic entities, in contrast to French that makes use of the preposition à in sentence (7).

4 Does this mean that the English and the French systems are regulated by completely independent and unrelated principles? The strong correspondence illustrated in sentences (1)-(6) pleads against this conclusion. In this article, I will propose similar 
notions to describe each couple of basic spatial prepositions in French and in English. Then, I will explain the discrepancies between the two systems by different extensions of these prepositions. Of course, their development depends on their competition with the other spatial prepositions in the system. The more prepositions there are in a system, the more limited their distribution will be. Therefore, in the absence of a preposition equivalent to to, the French preposition $\grave{a}$, in contrast to the English preposition at, extends its value from the introduction of actual localization of a target to the introduction of its prospective localization. This extension is valid for all the static spatial prepositions in French. Instead of introducing the prospective localization in the definition of the preposition $\grave{a}$-and redundantly in the definition of all the other French static spatial prepositions-, I will attribute this extension to a general principle of anticipation (section 1). In section 2, I will show that this principle applies to the English spatial prepositions, with the exception of at, on and in. The existence of these explicitly prospective prepositions in English but not in French will be attributed to the contrast between displacement verbs in the two languages. In section 3, I will investigate the relation between in/on and into/onto. I will claim that into and onto are compound words elaborating the meaning of to rather than the meaning of in and on. The order of the morphemes in into and onto is consistent with the formation of compound words in English. In my analysis of French prepositions (Vandeloise 1986, 1988, 1991), I assigned the preposition $\grave{a}$ to the expression of localization and the prepositions dans and sur to the expression of containment and support respectively. In English, in is often preferred to at to localize a target in a geographic entity. In section 4, this extension will be explained by a development of the notion of container from material entities to some portions of space that I will call spatial entities. A continuum will be established from the most typical containers to the most marginal. As it often happens, French and English impose boundaries between localization and containment at different points of the continuum.

\section{Principle of anticipation}

Vandeloise (1988) proposes two definitions for the static uses of the preposition à :

$\mathrm{A} 1: x$ est à $y$ if $x$ localizes $y$

A2: $x$ est $a$ $y$ if the positions of $x$ and $y$ are associated in a routine evoked by $y$.

In these rules, $x$ will be called the target of the preposition and $y$ its landmark. ${ }^{1}$

Rule A1 justifies the use of $a ̀$ in sentence (11) :

(11) L'enfant est à Paris

'The child is in Paris'

(12) * La cuiller est à la tasse

'The spoon is at the cup'

(13) *L'enfant est à l'arbre

'The child is at the tree'

(14) L'enfant est à l'arbre de la Sorcière

'The child is at the tree of the Witch'

8 The preposition à in sentence (11) is translated by in in English. A spatial landmark like Paris localizes a target if it coincides (partially) with the landmark. Since material entities cannot coincide, a material landmark can only localize contiguous targets or targets situated in its proximity. Those conditions are necessary but not sufficient. Indeed, in order to help to localize a target, the position of the landmark must be well established in 
the knowledge of the participants to the discourse. This is the case for geographic entities like Paris but not (without exceptional circumstances) for material entities like a spoon or a tree. Sentence (14), however, is acceptable because l'arbre de la Sorcière would not have received a name if its position was not well entrenched in the knowledge of the villagers.

Rule A2 applies to the following sentences :

(15) L'enfant est à l'école

(16) The child is at (the) school

(17) *Le banc est à l'école

(18) The bench is at the school

(19) Le banc est dans l'école

(20) The bench is in the school

Sentence (15) is appropriate even if it is used in the holidays, when the child is at the beach or in the mountains. In contrast, sentence (17) is unacceptable because, even if the bench is physically present in the school, it cannot learn to read. The prepositions dans or in must be used in this case. There is a strong parallelism between the routine usages in French and in English, even though this language may drop the definite article in sentence (16) and if sentence (18) is acceptable with the only. French also sometimes omits the definite article before the landmark, as in l'enfant est à table. Routine uses of the prepositions $\grave{a}$ and at may be considered as extensions of their spatial uses. ${ }^{2}$ I will not focus on these uses in this paper.

As it stands, rule A1 cannot apply to sentence (21):

(21) L'enfant va à Rome

Indeed, in this sentence, $\grave{a}$ does not introduce the actual position of the target but its prospective position at the issue of the displacement. A third usage rule A3 might apply to this sentence :

A3: $x$ va à $y$ if $y$ is the prospective location of $x$

However, as illustrated by sentences (22) and (23), this decision would imply a duplication of the usage rules for all static spatial French prepositions :

(22) L'enfant va dans la maison

'The child is going into the house'

(23) L'enfant va devant la maison

'The child is going in front of the house'

Indeed, like the preposition $\grave{a}$, the prepositions dans and devant introduce the prospective position of the target behind the verb aller. ${ }^{3}$ For this reason, the introduction of a principle of anticipation applying to all the spatial prepositions behind the verb aller is more economical :

Principle of anticipation (provisional formulation) : Prepositions describing the actual position of a static target describe similarly the prospective position of a mobile target behind the verb aller

16 This principle must be extended because, as illustrated by sentences (24)-(26), the verb aller is not alone to activate the principle of anticipation :

(24) L'enfant vient dans la maison

'The child is coming into the house'

(25) L'enfant monte sur le toit

'The child is climbing onto the roof'

(26) L'enfant part à Rome

'The child is leaving for Rome' 
Indeed, in sentences (24)-(26), the spatial prepositions introduce a prospective position of the target behind the verbs venir, monter and partir. The contrast between these uses and the corresponding static uses cannot be attributed to displacement alone since some displacement verbs like arriver introduce the actual position of the target :

(27) L'enfant arrive à Rome

'The child is arriving in Rome'

(28) L'enfant marche dans la forêt

'The child is walking in the forest'

In French, this is also true for verbs conveying the manner of displacement like marcher in sentence (28). In contrast to the English translation, this sentence cannot be used if the forest is the goal of the child. Rather than between static and kinetic verbs, the contrast stands between verbs introducing the prospective position of the target and verbs introducing its actual position. The complement of aller is mandatory and the position of its target is always prospective. On the contrary, arriver always introduces the actual position of the mobile target. Therefore, the principle of anticipation may be reformulated as follows :

Principle of anticipation (second provisory formulation): Prepositions describing the actual position of a static target describe similarly the prospective position of a mobile target behind displacement verbs compatible with the prospective localization of the target

20 The target is the subject of the verb for the voluntary displacements and its direct object for the verbs of cause of displacement like mettre ('put') :

(29) L'enfant met le livre sur la table

'The child puts the book on the table'

21 As it is formulated, the principle of anticipation cannot apply to the verbs of manner of displacement (like marcher) and the verb arriver.

22 However, this version of the principle of anticipation cannot be definitive. Indeed, as illustrated by sentence (31), this principle does not apply for all the spatial prepositions behind partir. Sentence (33) demonstrates that it is also true for the verbs monter and descendre :

(30) L'enfant part sur la colline

'The child is going out onto the hill'

(31) L'enfant part devant la colline

'The child is going out in front of the hill'

(32) L'enfant monte/descend dans la classe

'The child is going up/down in the classroom'

(33) L'enfant monte/descend devant la classe

'The child is going up/down in the classroom'

Whereas sentences (30) and (32), with prepositions sur and dans, are very likely to trigger the principle of anticipation and to provide the prospective location of the target, the preposition devant in sentences (31) and (33) does not signal its prospective position -as it would behind aller and venir- but its actual position. ${ }^{4}$

In order to explain this pattern, a distinction must be established between the locative prepositional phrases behind a displacement verb. As illustrated by sentences (34)-(36), these verbs may be followed by different locative prepositional phrases:

(34) L'enfant part

'The child sets off' 
(35) L'enfant part d'ici

'The child sets off from here'

(36) L'enfant part à l'épicerie

'The child heads off to the grocery'

D'ici in sentence (35) makes explicit a localization relation that is implicit in sentence (34). Laur (1993) calls these locative complements lieu de référence verbal ('verbal reference place'). The verbal reference place is part of the meaning of the verb. The location conveyed by à l'épicerie is a locative complement different from the verbal reference place. Even though the verbal reference place of partir is the actual origin of the displacement, it is compatible with the prospective localization of the target in sentence (36). But, for this verb, the principle of anticipation applies only to à, sur and dans. This means that the principle of anticipation applies to all the static spatial prepositions only if the verbal reference place is prospective. This is true for aller and venir but not for partir, monter and descendre. Consequently, the definitive version of the principle of anticipation may be stated as follows :

Principle of anticipation: The basic spatial prepositions describing the actual position of a static target describe similarly the prospective position of a mobile target behind displacement compatible with the prospective localization of the target. If the verbal reference place is prospective, this is true for all the static spatial prepositions

As their French correspondents, it will appear in section 3 that the English prepositions at, on and in behave differently from the other static spatial prepositions relative to the principle of anticipation. This point reinforces the correspondence between the basic spatial prepositions in French and in English.

With the principle of anticipation, the kinetic uses of a spatial preposition appear dependent on its static uses. Could we instead contemplate the possibility of a "principle of stabilization" in which all the static uses of a spatial preposition would be the final result of a preceding displacement $?^{5}$ If the application of the principle of anticipation were grounded on the contrast between static and kinetic, one might be tempted by this alternative. Indeed, languages often privilege the expression of movement over the expression of immobility. However, the example of the verb arriver shows that displacement is not a sufficient condition to trigger the principle of anticipation. The pertinent contrast is between actual localization and prospective localization. This pleads for the principle of anticipation over a principle of stabilization since spatial prepositions have probably been used in the immediate context of enunciation before being applied outside the visual field.

\section{The English preposition to and the prospective localization of the target}

28 In sentences (37)-(39), the prepositions to, into and onto introduce explicitly the prospective position of a mobile target :

(37) The child is walking to the theater

(38) The cat is jumping onto the table

(39) The child goes into the house 
French does not allow introducing the prospective position of a target with a verb of manner of movement followed by a preposition. ${ }^{6}$ The best approximations would involve prepositions vers ('toward') or jusqu'à ('up to'), like in sentences (40) and (41) :

(40) L'enfant marche vers le cinema

(41) L'enfant marche jusqu'au cinéma

But there is no warranty in sentence (40) that the child will not change his direction before reaching the theater and sentence (41) would be true if the child stopped just before the theater. The best translation of sentence (37) is given by sentence (42) :

(42) L'enfant va au cinéma en marchant

31 The spatial use of the preposition to abide by rule $\mathrm{T}$, in which $\mathrm{V}$ may be a verb of manner of displacement (like drive) or a verb of displacement (like go) :

$\mathrm{T}: x \mathrm{~V}$ to $y$ if $y$ localizes the prospective position of $x$

In contrast to sentences (37)-(39), sentences (43) and (44) are ambiguous :

(43) The cat is running under the bridge

(44) The child walks in front of the house

Indeed, in these sentences, the prepositions under and in front can introduce the actual position of the target as well as its prospective location. This ambiguity stands for all the static spatial prepositions of English with the exception of at, on and in. These prepositions are normally ${ }^{7}$ replaced by to, onto and into when the localization of the target is prospective. In other words, the principle of anticipation applies to English static prepositions when there is no corresponding preposition introducing explicitly the prospective position of the target. As illustrated by sentences (43) and (44), the principle of anticipation applies to the verbs of manner of displacement as well as to the appropriate verbs of displacement. The principle of anticipation for English can be formulated in the following way:

Principle of anticipation : If there is no corresponding preposition introducing the prospective position of the target, prepositions describing the actual position of a static target describe similarly the prospective position of a mobile target behind displacement verbs compatible with the prospective localization of the target and behind verbs of manner of displacement The comparison of the prepositional systems in French and in English raises two questions : -Why, in contrast to French, does English have three explicit prepositions to, onto and into to indicate the prospective position of a target? -Why is the adjunction of to limited to on and in, making * underto or *aboveto impossible?

An answer to the first question may be found in the comparison of the verbal systems of the two languages. It is well known that English is a satellite-framed language whereas French is a verb-framed language (Talmy 2000). This means that, in English, the verb conveys the manner of displacement while the path is expressed by particles such as up, off, etc. In French, in contrast, verbs of displacement express the path and the manner of displacement is not regularly specified. The contrast appears in the following examples :

(45) L'enfant va au cinema

(46) ?The child is going to the theater.

(47) The child is walking to the theater

In the French sentence (45), $v a$ announces the prospective end of the path introduced by $a u$ and triggers the principle of anticipation. In English, sentence (47), with the manner of 
displacement verb walk, sounds more natural than sentence (46), with the displacement verb go. But, in contrast to directional verbs, walk cannot specify alone whether the localization complement behind it is an origin, a path or a goal. This may explain why a specific preposition to must be chosen to introduce the prospective localization of the target. Note that, in Old English, the preposition cet, corresponding to at, has long been in concurrence with to to introduce the prospective localization of the target. The preposition to imposes itself in the seventeenth century only (Lindkvist 1978).

Descriptively, the English version of the principle of anticipation applies correctly to the static spatial prepositions at the exclusion of $a t$, in and on. In the framework of Distributed Morphology, Thomas (note 5, p. 164) asserts that "There seems no reason in principle why under should not have a telic correlate (perhaps *underto) in the same way as does in. It just happens that there is no such Vocabulary item in English". ${ }^{8}$ This explanation by the idiosyncrasy of the lexicon may be judged sufficient. However, one would like to understand why the introduction of the prospective position of the target is different from the introduction of its actual position for to, into and onto only. One explanation might be that the goal of a mobile target often is outside the visual field. In these circumstances, the most specific spatial prepositions like in front or under are rarely needed since basic spatial prepositions provide enough information. In French, $\grave{a}-$ the general preposition of localization- normally fulfills this role. To may be considered as the prospective equivalent of at in English. As we will see in section 4, the preposition in is used to express actual localization in English more often than in French. This may account for the formation of into. Furthermore, reaching a goal is an intentional act. Like sur and dans in French, on and in are functional prepositions conveying support and containment. These functions are well adapted to motivate voluntary or caused trajectories. Even though none of these explanations may be considered sufficient, they show that there are more reasons to reserve the explicit lexicalization of the prospective position of a target to the basic spatial prepositions at, in and on than to the other spatial prepositions. Remember that in the final version of the French principle of anticipation, $\grave{a}$, sur and dans also behave differently from the other static spatial prepositions.

\section{The relations between in and into and between on and onto}

From their morphology, it is clear that, diachronically, the prepositions in and on precede the complex prepositions into and onto. In this section, I will attempt to decide whether these complex prepositions should be considered as specifications of to or as specifications of in and on. Linguists working in the framework of Distributed Morphology (Thomas 2005) consider that to should be before in and on in these complex prepositions instead of behind them. To conclude this section, I will propose an alternative in which into and onto are considered as compound words constituted of two free morphemes. Their order abides directly by the rules of English morphology.

41 As illustrated by sentences (48)-(51), the introduction of the prospective position of a target inside or on a landmark is not exclusively reserved to into and onto :

(48) She jumped on the bed

(49) He fell in the lake

(50) ?He came in the living room

(51) ?He ran in the house 
According to Thomas (2005), these sentences are ambiguous because they can localize the actual or the prospective position of the target. However, the author points out that the preposition in needs special circumstances in order to express directionality. Sentences (48) and (49) are ambiguous because the verbs jump and fall have an intrinsic directionality, upward and downward respectively. This is also the case for come (displacement toward the speaker) but the author does not provide an explanation for the diminished acceptability of sentence (50). Finally, in and on may introduce a prospective localization behind verbs of manner of displacement like walk or run "with a 'light' (in some sense) manner component" (Thomas 2005 : 151). Sentences (52) and (53), in contrast, cannot have a directional interpretation, because of the 'heavy' manner component of dance and float :

(52) She danced on the stage

(53) The bottle floated in the lock basin

These data are compatible with an incomplete process of lexical formation by division (see (McLaury 1991), and (Vandeloise 2010) reproduced in this special issue). In this process, a new appellation is attributed to a group of prominent members of a lexical category. First, the new appellation coexists with the original appellation. After a while, the new appellation supersedes the old one for the prominent members and the old appellation is constrained to the other members. When the division is complete, a new lexical category is created. Before the creation of into, one may postulate that a general word -let us call it IN - introduced the actual position of the target as well as its prospective position, thanks to the principle of anticipation. At the beginning, into was used conjointly with IN by the most young or creative speakers, each time a further clue was necessary to indicate the directionality and dissipate the ambiguity between the actual and the prospective position of the target. Latter, behind the "heavy" verbs of manner of movement, the use of into instead of IN became mandatory. At this point, the general lexical category $I N$ is split into two categories : in -as it is now used in Englishand into. Figure 1 represents this development. At stage 1, IN can always be used instead of its hyponym into. At stage 2, into becomes mandatory in most cases and the extension of IN is restricted to the extension of in. However, when the directionality is intrinsically conveyed by the verb, into did not completely eradicate the use of in. Behind verbs like jump and fall, then, the preposition in behave ambiguously like the French preposition dans. The intersection between the two categories accounts for sentences (48) and (49), in which in can still introduce directionality. 


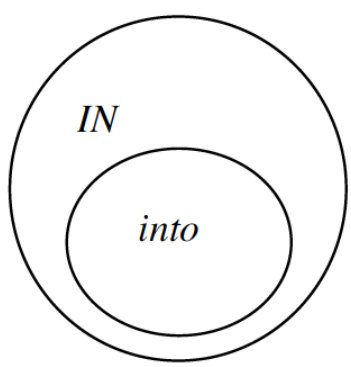

Stage 1

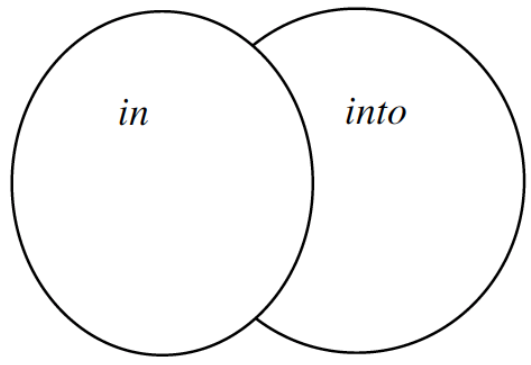

Stage 2 general preposition IN. At stage 2, however, in and into are independent prepositions. As a matter of fact, the possibility of using into makes the use of in impossible. Indeed, one can put a pencil into a box only if it is not in the box. And conversely, the possibility of using in makes the use of into impossible since you cannot put a pencil in a box if it is already in the box. substitution of $x$ by $y$ is always possible but that the reverse is not true. Verbs of voluntary displacements lead to the conclusion according to which the complex prepositions into and onto are developments of to. Indeed, each time into or onto are used behind these verbs, to can be used as well, even though with less precision:

(54) The child is going into the grocery

(55) The child is going to the grocery

(56) The cat is jumping onto the table

(57) The cat is jumping to the table

Therefore, into and onto imply to but the reverse is not true : sentences (55) and (57) do not always imply sentences (54) and (56). This is a direct consequence of the meanings of these prepositions. Indeed, compared to the usage rule $\mathrm{T}$ for to, repeated here, the usage rules IT and OT for the spatial uses of into and onto may be formulated as follows :

$\mathrm{T}: x \mathrm{~V}$ to $y$ if $y$ localizes the prospective position of $x$

IT : $x V$ into $y$ if $y$ is the prospective container of $x$

OT : $x V$ onto $y$ if $y$ is the prospective support of $x^{9}$

Rules IT and OT clearly specify rule $\mathrm{T}$ since containers and supports are specific types of position.

As illustrated by sentences (58)-(61), however, some verbs of cause of displacement behave differently :

(58) The child puts the pencil in/into the box

(59) *The child puts the pencil to the box

(60) The child puts the cup on/onto the table

(61) *The child puts the cup to the table

True, the use of in and on in sentences (58) and (60) is often preferred to into and onto, that may look literary or affected. Nevertheless, how could into and onto be elaborations of to if they cannot be replaced by this preposition? The answer might be that the distance 
between the actual position of the speaker and the prospective position involved in rule $\mathrm{T}$ must be larger than the distance between the speaker and the prospective container or support involved in rules IT and OT. Therefore, the impossibility of using to behind verbs like put or place might be attributed to the proximity imposed by these verbs between the agent, the target and the landmark. Verbs of cause of displacement like throw or smash do not impose this constraint on the distance between the position of the event of throwing or smashing and the prospective position of the target. In this case, as illustrated by sentences (63) and (65), to can replace into or onto :

(62) The child throws the ball into the pool

(63) The child throws the ball to the pool

(64) The child smashes the ball onto the baseline

(65) The child smashes the ball to the baseline

Therefore, the unacceptability of sentences (59) and (61) may be attributed to the difference between prospective positions on the one hand and prospective containers and supports on the other hand. A container or a support is prospective as long as it does not contain or support. The distance between the actual and the prospective position of the target does not matter. This factor is determinant in the use of to.

51 At the issue of this section, a development to $\rightarrow$ into, onto appears more likely than a development in $\rightarrow$ into, and on $\rightarrow$ onto. The order of the morphemes in into and onto creates a problem for the linguists working in the framework of Distributed Morphology like Thomas (2005) because this order does not correspond to their interpretation of into and onto in terms of projections. Consequently, they use different transformations to explain why the apparent structure of English does not correspond to its 'deep structure'. However, since to, in and on are free morphemes, into and onto may be considered as compound words. This alternative directly corresponds to the hypothesis of a development to $\rightarrow$ into, onto. Indeed, in many compound words, one component is determined by the other component that is a determiner. These relations between components occur in reverse order in French and in English. Whereas the order in French is [determined + determiner] (poisson-chat means a fish that looks like a cat), the order in the English correspondent catfish is reversed: [determiner + determined]. According to this pattern, the determined in into and onto should be to and the determiners in and on respectively. This order of the morphemes is consistent with the formation of compound words in English.

\section{From control to localization}

52 A material entity is mainly controlled by another material entity through containment (control in more than one direction) or through support (control along the vertical direction). These types of control are indirectly associated to localization since an object mainly controls the objects in its proximity. In first, I will examine the connections between localization and containment. At the end of this section, I will quickly turn to the relation between localization and support.

53 In rule $\mathrm{A}_{1}$, the preposition $\grave{a}$ is associated to localization (Vandeloise 1988). The spatial uses of the French preposition dans abide by the usage rule $D_{m}$ when the landmark is a material entity (Vandeloise 1986). A second rule $\mathrm{D}_{\mathrm{s}}$ will be proposed latter for the cases in which the landmark is a spatial entity : 
$\mathrm{D}_{\mathrm{m}}$ : $x$ est dans (a material entity) $y$ if $x$ and $y$ are the first and the second term of the

relationship C(ontainer)/c(ontent)

It would be easier to say that $x$ est dans $y$ if $y$ contains $x$ but this definition would not cover uses like la lampe est dans la douille ('the lamp is in the socket') since the socket does not contain the lamp. The relationship $\mathrm{C} / \mathrm{c}$ is what I call a complex primitive. It is primitive because prelinguistic infants are globally aware of the relation of containment. It is complex because its description requires many propositions such as :

- (a) The position of the content relative to the container does not change when the container is moving

- (b) The container prevents the content from transgressing its limits in more than one direction

- (c) Before containment, the content moves toward the container rather than the reverse

- (d) The container envelops the content

- (e) The container protects the content

- (f) The container hides the content

These attributes constitute the traits of the family resemblance $\mathrm{C} / \mathrm{c}$ that describes the complex primitive $\mathrm{C} / \mathrm{c}$. The prototypical cases of containment constitute the basis of the complex primitive. They satisfy all the traits in the family resemblance. This is not the case for marginal cases of the relationship $\mathrm{C} / \mathrm{c}$ that satisfy a few traits only. The lamp in the socket, for example, satisfies traits (a), (b) and (c) but not traits (d), (e) and (f). In sentence (66), traits (d), (e) and (f) are respected and sentence (67) satisfies traits (a), (b) and (d) (Vandeloise $2005: 225)$ :

(66) Le cadeau est dans l'emballage

'The gift is in the wrapping'

(67) La louche est dans la soupe

'The ladle is in the soup'

Complex primitives bear some connection with the prepackaged units that Talmy (1983, 1985) associates to basic prepositions since they have many facets. However, their genesis is very different. Indeed, "prepackaged units" presuppose that the elements of the package exist before the formation of the package. In contrast, complex primitives are first understood globally by infants, through the function or the needs they fulfill. Afterwards, they are analyzed and the aspects through which they may be recognized are isolated. Similarly to dans, the preposition sur is associated to a complex primitive, the relationship $\mathrm{B}($ earer)/b(urden) (Vandeloise 1991). Its usage rule may be formulated as follows :

$\mathrm{S}: x$ est sur $y$ if $x$ and $y$ are the first and the second term of the relationship B/b

57 As exemplified by the English translations of sentences (66) and (67), the spatial uses of dans and in often behave in the same way. This is especially true when the target and the landmark are material entities. But there are interesting discrepancies when spatial entities are involved in the relationship, as illustrated by the following examples :
(68) L'enfant est au Canada
(69) The child is in Canada
(70) L'enfant est à Paris ${ }^{10}$
(71) The child is in Paris

In sentences (69) and (71), the preposition in stands for the preposition $\grave{a}^{11}$ However, in the case of countries, as illustrated by sentences (72) and (73), en is used instead of au when the name of the country is feminine or begins by a vowel: 
(72) L'enfant est en France

(73) Juan est en Argentine

French, the preposition dans has replaced en in most of its spatial uses. Notionally, en might be considered the normal preposition to introduce countries since au is the result of a morphological accident resulting from the evolution of en le : en le $>e l>e u>o u$ which was confused with au. Despite these divergences, I will associate the English preposition in to the relationship $\mathrm{C} / \mathrm{c}$. The differences between the two languages will be attributed to different extensions of the family resemblance $\mathrm{C} / \mathrm{c}$.

60 Connections may be established between the notion of localization and the notion of containment. In particular, because of traits (a), (b) and (d), the notion of container can extend progressively to the notion of place. English goes further in this extension than French. Localization has also some similarities with containment because an entity is affected by the place in which it is located. In his famous definition of place (Physics, book IV), Aristotle closely associates place and container :

Place is the limit of the containing body with which the contained body is in contact 12

61 In Aristotle's Physics, the localization of a material entity is essentially relative to the material entities in its proximity. The most prominent relations between objects occur between the burden and its bearer on the one hand, and between the content and its container on the other hand. By relating the notion of place to material objects, Aristotle tries to get rid of space and of spatial entities. This may work for a limited space inside the visual field but the description of prospective positions cannot be based on material entities only. A system of orthogonal axes emerging from a fixed point will prove necessary to keep track of all the positions in the universe. Such a system was first suggested in the Middle Age by Saint Thomas Aquinus.

62 In the domain of material entities, in and dans behave essentially in the same way. Discrepancies appear when there is a spatial entity among the arguments of dans or in. This may be explained by the subjectivity of spatial entities and the nature of their boundaries. Indeed, the boundaries of material entities impose themselves on the speaker. ${ }^{13}$ Spatial entities, in contrast, have no material boundaries. At first, spatial entities are created by speakers when a portion of space affects their behavior or determine the nature of the material entities that occupy this portion of space. These portions can be benefic or malefic. In contrast to material entities definite by their boundaries, most spatial entities determine their boundaries. Like colors and natural categories, they have a center in which their influence is more intensely felt and fuzzy boundaries where the effects of the zone fade up. One does not go from a spatial entity to another because of a crossing of boundary but one have the feeling of a boundary because one goes from one spatial entity to another spatial entity. Countries, with their well defined frontiers defended by customs and armies, are closer to material entities than other spatial entities, even though most of their boundaries materialize themselves mainly on maps. But nations are built by organized and administrative societies and their boundaries are defined a posteriori. Spatial entities with clear boundaries fulfill better the enclosure of a target required by the trait (d) of the family resemblance $\mathrm{C} / \mathrm{c}$. Other spatial entities, like the world or the universe -the uncontained container of everything, as Aristotle puts it-, are so large that their boundaries do not exist or cannot be reached.

Corela, HS-23 | 2017 
They do not control the targets by their boundaries as containers do but by their immensity to which nothing can escape :

(74) La terre est dans l'univers

'The earth is in the universe'

(75) L'oiseau est dans le ciel

'The bird is in the sky'

63 Outside geometry, they are no purely spatial entities. In a large forest, forest designates a spatial entity, the place where the trees stand. But in a high forest, the word forest rather designates a material collective entity, the trees in the forest. Industrial zone is also ambiguous between a place and the material entities standing in this place. The same is true for countries like France or cities like Paris : a country or a city is together a place and the entities - citizens (with cats and dogs) and buildings- standing in this place. In contrast to material entities, spatial entities can only control the target indirectly, through its climate or the material entities that occupy it. In the following examples, the landmark may be considered as a zone of influence rather than as a zone of research :

(76) L'enfant est dans la forêt

'The child is in the forest'

(77) L'enfant est dans le désert

'The child is in the desert'

(78) La maison est dans les vignobles

'The house is in the vineyards'

(79) L'hôtel est dans la zone industrielle

'The hotel is in the industrial zone'

These sentences do not localize the target but rather describe the consequences that result from its position : the child may be in danger in the forest or thirsty in the desert; the circumstances are welcome for the house in the vineyards but detrimental for the hotel in the industrial zone.

Any portion of space can be designated in French with words such as perimeter or region:

(80) Les armes sont interdites dans ce périmètre

'Arms are forbidden in this perimeter'

(81) Il y a beaucoup de châteaux dans cette région

'There are many castles in this region'

As for the preceding sentences, the use of the preposition dans in sentences (76)-(81) is explained by the zone of influence associated to the spatial entities virtually delineated. These delineations would not make sense if it were not the intention of the speaker to attribute some qualities to the delineated zone. Therefore, the targets of sentences (76)(81) are affected by the spatial entities in which they are located. Even though these examples may be justified by the relationship $\mathrm{C} / \mathrm{c}$ because they satisfy a combination of its attributes, I propose a more specific rule Ds (Vandeloise 1995):

$\mathrm{D}_{\mathrm{s}}: x$ est dans (a spatial entity) $y$ if $x$ is affected by the zone of influence associated to

$y$

67 This rule paves the way for an extension of the preposition dans from the expression of containment to the expression of the dependence between the target and the landmark. This extension might be instrumental in the interpretation of many metaphorical uses of dans.

68 In the examples below, material and spatial entities are ranked relative to their behaviour with à, dans, at and in : 


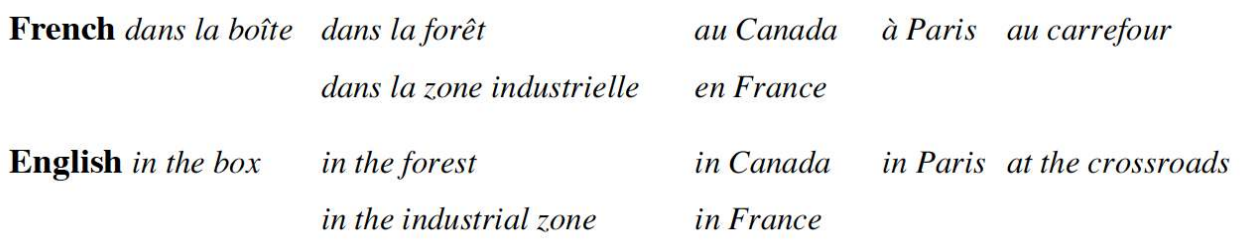

Prototypical containment occurs when a material entity controls a material entity enclosed in its boundaries. Prototypical localization is provided by coincidence, contiguity or proximity of a target with a landmark as punctual as possible. French and English agree in these two cases, illustrated by the box and the crossroads: dans corresponds to in and $\grave{a}$ corresponds to at. With the exception of the box, all the landmarks in the data may designate spatial entities.

70 In contrast to what happens for countries and cities, the French preposition dans as well as the English preposition in can be used for zones like forest and the industrial zones. Why is there agreement between French and English with zones of influence but not with countries and cities for which the English preposition in is translated by French prepositions en or à? As far as boundaries are concerned, countries, with their sharp frontiers, fulfill better the role of container than zones of influence whose boundaries often are fuzzy. Furthermore, countries and cities may also be considered as zones of influence that determine the behavior and the habits of their citizens or visitors. In this way, they share properties with the containers. English focuses on these similarities when in introduces countries and cities. Rather than in containment, the justification of the discrepancy between zone of influences and countries and cities in French must be looked for in the function of localization. Indeed, if countries and cities are as good containers as zone of influence, they are much better tailored to localize a target because they are attributed a proper name and because of the use of maps. Their quality as landmarks justifies the use of $\grave{a}$. The most limited a landmark is, the most precisely it will localize the target. ${ }^{14}$ Obviously, you will find a friend more easily if you know in which city he is staying than if you know on which continent he is. This may explain why there is some leeway in the case of many countries introduced by en whereas the French preposition of localization $\grave{a}$ is always used in front of cities like Paris.

71 The borderline between localization and containment is a zone of turbulence as the history of French and English testifies. Indeed, in French, the preposition en, derived from the Latin preposition in, was used in front of all geographic entities until the twelfth century. Then, the preposition à imposes itself in front of cities. Due to the morphological evolution of French, $a u$ (the contraction of $\grave{a}+l e$ ) also introduces masculine names of countries beginning with a consonant but en remains alive for the other names of countries. English has also wavered in the introduction of countries and cities. In old English as in Modern English, the preposition $œ t$-the ancestor of at- was not used to introduce cities and countries. It took this function in Middle English but latter, in Early Modern English, it was replaced by in (Lindkvist 1978). Interestingly, in was first preferred to at with large cities and when a displacement of the target was not suggested. If there is displacement, at may still introduce cities in Modern English, as illustrated by an example of Lindkvist (1978) :

(82) The journey began at London and finished at Nothingam

This predilection of at for movement should not surprise since the contrast between that preposition and to is not based on the difference between static and kinetic but on the 
contrast of the actual localization of the target and its prospective position. In keeping with the preference of at for limited landmarks, the encounter of a mobile limited target with a landmark -as large may it be-is limited. This explains the contrast between living on Park Blvd. and living at Park Blvd. and Government. Indeed, Park Blvd. may be considered as a virtual mobile entity that cuts Government Street at a point. The preposition at can also introduce a prominent entity in a city. Therefore, a tourist may be in Cambridge but a student is at Cambridge ( $s^{\prime}$ College). Obviously, Cambridge College is a more limited landmark than the whole city. Finally, Lindkvist notes that one may say that there is 49 degrees at London. London is certainly not a small landmark but here, we have a rare case in which the target (the temperature) coincides totally with the landmark. If one admits that the target determines the measure unit according to which the size of the landmark is evaluated, total coincidence of the target with the landmark corresponds to one unit, whatever the size of this unit. In order to make explicit the difference between $\grave{a}$ and at as far as localization is concerned, the following usage rule may be proposed:

AT $: x$ is at $y$ if $y$ is a limited landmark that localizes the position of $x$

This rule differs from the corresponding usage rule $\mathrm{A} 1$ by the addition of limited landmark. A punctual landmark is an ideal limited landmark but the tolerated extension depends on the context as illustrated by 49 degrees in London.

The extensions of on or sur from support to localization are less frequent than for in and dans. They occur mainly with paths and islands :
(83) La maison est sur la route
(84) The house is on the road
(85) La maison est dans la rue du Gouvernement
(86) The house is on Government street
(87) La maison est sur le boulevard
(88) The house is on the boulevard
(89) L'enfant est sur l'île
(90) The child is on the island

Paths are normally introduced by sur in French, but, as illustrated by sentence (85), on is translated by dans in front of rue as well as in front of ruelle ('alley'). This may be explained because, in contrast to roads, streets are lined with houses that create an enclosed space. This is also true for boulevards but, maybe because of their width, sur is used in sentence (87). When they are not followed by a name, one may wonder whether roads and islands must be considered as spatial entities or as material supports. The role of support in the case of islands is reinforced by the presence of the sea that cannot support walkers as earth does. The landmark of sentence (91) is certainly a spatial entity :

(91) Le point est sur la ligne

'The point is on the line'

76 But paper is a material support on which points and lines are drawn. Therefore, it might not be too farfetched to claim that the trace of the line on the paper supports the trace of the point.

\section{Conclusions}

77 The landmark of the French preposition à localizes its target (rule A1) or associates it to a routine conveyed by the landmark (rule A2). For material entities, the prepositions dans and sur associate their target and their landmark in the relationship C/c (rule Dm) and B/ 
$\mathrm{b}$ (rule S) respectively. If the landmark of the preposition dans is a spatial entity, the target is involved in the zone of influence associated to the landmark (rule Ds). With material static entities, the prototypical spatial uses of the prepositions at, in and on in English correspond to the prototypical uses of $\grave{a}$, dans and sur in French. The relationships $\mathrm{c} / \mathrm{c}$ and $\mathrm{B} / \mathrm{b}$ are complex primitives, globally understood by children at an early stage and characterized by a list of attributes that function as the traits of a family resemblance. The prototypical uses of dans and in and the prototypical uses of sur and on meet all the traits of the family resemblances $\mathrm{C} / \mathrm{c}$ and $\mathrm{B} / \mathrm{b}$ respectively. Their marginal uses satisfy only combinations of these traits. The combinations sanctioned by French and English may be different. The use of in with spatial entities is more extended than the use of dans. In keeping with the rule Ds, both French and English use dans or in in front of zones of influence like forests or regions. But English uses in to introduce countries (for which French uses $\grave{a}$ or en) and in front of cities (for which French uses à). This means that French treats countries and cities as landmarks susceptible of localization whereas English treats them as zone of influence and container-like entities. Clearly, this discrepancy indicates that the choice of prepositions is not univocally determined by the reality they represent. However, this does not mean that the choices made by languages are arbitrary. Localization and containment may be considered as two concurrent motivations that act differently in French and in English. As a matter of fact, we are here in a zone of turbulence as the history of both languages testifies. Indeed, in English, cities and countries have been introduced by œet (the ancestor of at) until the seventeenth century and in French, the preposition en used in front of many countries derives from the Latin preposition in often translated by dans.

78 French uses the same spatial prepositions to convey the actual position of a target and its prospective position at the issue of a displacement. Instead of introducing two usage rules for each static spatial preposition, I explain this extension by a general principle of anticipation. This principle may be justified by the fact that the best way of localizing and reaching a mobile target is to indicate the place where it will stop. English, in contrast, can make the prospective position of the target explicit through the prepositions to, into and onto. Here also, the history of English indicates some hesitations since, until the seventeenth century, œet could be used for to. Furthermore, English is not impervious to the principle of anticipation since, with the exception of to, into and onto, all the other static spatial prepositions, like under, can introduce the actual position of the target as well as its prospective position. For this reason, in section 2, I propose a version of the principle of anticipation adapted to English.

79 According to the interpretation of into and onto proposed by Distributed Morphology, the morpheme to should not be after the morphemes in and on but before, like in to-in and toon. Inside their theory, they propose different mechanisms to explain this "superficial" anomaly. In section 3, I present into and onto as elaborations of to. French only proposes a distinction between localization (à) and control (sur, dans). This language establishes the difference between the actual and the prospective position of the target through the principle of anticipation. This contrast is explicitly marked by to, onto and into in English. Their connections with at, on and in appear in the diagram below : 


\section{control}

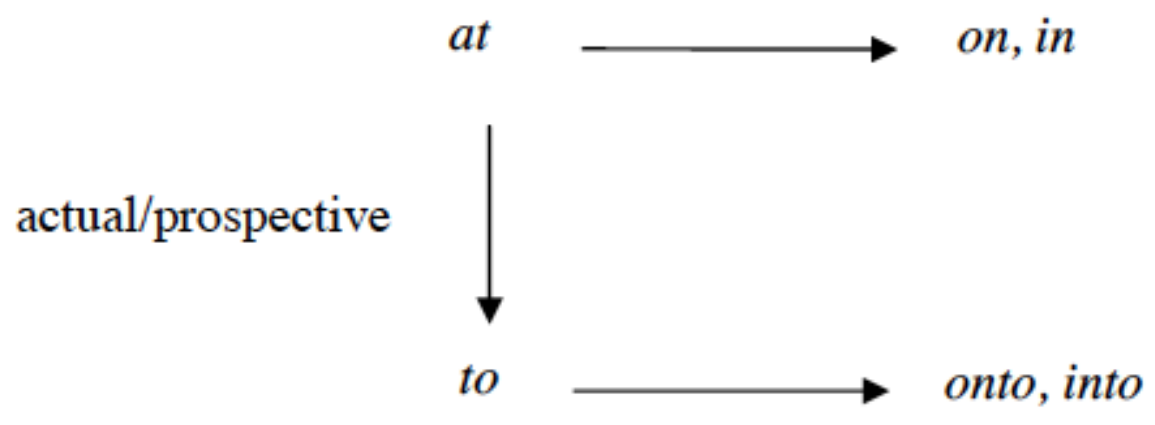

80

The horizontal arrow at the bottom of the diagram indicates that, as claimed in section 3 , into and onto are developments of to rather than of in and on. If this proposal is true, onto and into directly abide by the rules of English morphology. Indeed, they may be considered as compound words with two free morphemes. In a compound word like catfish, the first morpheme cat is a determiner for the second morpheme fish since a catfish is a fish that looks like a cat. According to my hypothesis, the same process is true for into and onto.

81 The basis for the comparison proposed in this article is a preceding extensive analysis of French prepositions (Vandeloise 1987, 1991). Therefore, English prepositions are viewed through a prism that might bias their analysis. A comparison going from English to French could lead to different conclusions. In particular, the role of dimensionality in the distribution of basic spatial prepositions seems more important in English than in French. This is certainly true for the preposition at that, in contrast to $\grave{a}$ that is used in front of countries and cities, is restricted to punctual -or zero-dimensional- landmarks. The connection of at with restricted, welldelimited entities also appears behind the verbs aim and look, one of the first uses of the preposition at by children.

The preposition on can also be used with linear -one-dimensional- landmarks, like in the house on the street, for which sur would not be acceptable in French. From a synchronic point of view, then, the role of geometric factors in the use of spatial prepositions, together with functional ${ }^{15}$ and dynamic factors, is inescapable (Deane 1993, 2005, Navarro-Ferrando 2002, Feist 2004). However, besides the synchronic point of view, this article must be understood in the perspective of logical diachrony (Vandeloise 1991). It is assumed in this framework that basic spatial prepositions emerge from a simple impetus, globally understood, that is afterward decomposed into its different attributes. Whereas dimensionality can be considered as an attribute of localization or of the relationships $\mathrm{C} / \mathrm{c}$ and $\mathrm{B} / \mathrm{b}$, the reverse is not true. Therefore, in the framework of logical diachrony, I maintain the priority of these relations. 


\section{BIBLIOGRAPHY}

Clark, H.H. (1973). Space, time, semantics and the child. In T.E. Moore (Ed.), Cognitive development and the acquisition of language. New York : Academic Press, 27-63.

Deane, P. (1993). At, by, to and past : an essay in Multimodal Image Theory. In Proceedings of the Annual Meeting of the Berkeley Linguistic Society, $19: 112-124$.

Deane, P. (2005). Multimodal spatial representation : on the semantic unity of over. In B. Hampe (Ed.), From perception to meaning : image schemas in cognitive linguistics. Berlin : Mouton de Gruyter, 235-282.

Dewell, R. (2005). Dynamic patterns of containment. In B. Hampe (Ed.), From perception to meaning : image schemas in cognitive linguistics. Berlin : Mouton de Gruyter, 369-394.

Feist, M.I. (2004). Talking about space : a cross-linguistic perspective. In K.D. Forbus, D. Gentner \& T. Regier (Eds.), Proceedings of the Twenty-Sixth Annual Meeting of the Cognitive Science Society. Mahwah, NJ : Lawrence Erlbaum, 375-380.

Feist, M.I. (2010). Inside in and on : typological and psycholinguistic perspectives. In V. Evans \& P. Chilton (Eds.), Language, cognition and space : the state of the art and new directions. London : Equinox, 95-114.

Gougenheim, G. (1959). Y a-t-il des prépositions vides en français? Le Français Moderne, 27(1) : $1-25$.

Husserl, E. (1907). Chose et espace, Leçons de 1907, traduit par J.F. Lavigne. Paris : Presses Universitaires de France.

Langacker, R.W. (1987). Foundations of Cognitive Grammar I : theoretical prerequisites. Stanford, CA : Stanford University Press.

Laur, D. (1993). La relation entre le verbe et la préposition dans la sémantique du déplacement. Langages, $110: 47-67$.

Lindkvist, K.G. (1978). AT versus ON, IN, BY : on the early history of spatial AT and certain primary ideas distinguishing AT from ON, IN, BY. Stockholm : Almqvist and Wiksell International.

MacLaury, R. (1991). Social and cognitive motivation of change : measuring variability in color semantics. Language, 67(1):34-62.

Navarro-Ferrando, I. (2002). Towards a description of the meaning of at. In H. Cuyckens \& G. Radden (Eds.), Perspectives on prepositions. Tübingen : Max Niemeyer Verlag, 211-230.

Talmy, L. (1983). How language structures space. In H.L. Pick \& L.P. Acredolo (Eds.), Spatial orientation : theory, research and application. New York : Plenum.

Talmy, L. (1985). Lexicalization patterns : semantic structure in lexical forms. In T. Shopen (Ed.), Language typology and syntactic description (Vol. 3) : grammatical categories and the lexicon.

Cambridge : Cambridge University Press, 57-143.

Talmy, L. (2000). Towards a cognitive semantics. Cambridge, MA : The MIT Press.

Thomas, E. (2005). On 'syntactic' versus 'semantic' telicity : evidence from in and on. Belgian Journal of Linguistics, $18: 145-166$. 
Vandeloise, C. (1986). L'espace en français : sémantique des prépositions spatiales. Paris : Editions du Seuil.

Vandeloise, C. (1987). La préposition à et le principe d'anticipation. Langue Française, 76 : 77-111.

Vandeloise, C. (1988). Les usages spatiaux statiques de la préposition à. Cahiers de Lexicologie, 53 : 119-148.

Vandeloise, C. (1991). Spatial prepositions : a case study in French. Chicago, IL : The University of Chicago Press.

Vandeloise, C. (1994). Methodology and analyses of the preposition in. Cognitive Linguistics, 5(2) : 157-184.

Vandeloise, C. (1995). De la matière à l'espace : la préposition dans. Cahiers de Grammaire, 20 : $123-45$.

Vandeloise, C. (2001). Aristote et le lexique de l'espace : rencontres entre la physique grecque et la linguistique cognitive. Stanford, CA : CSLI.

Vandeloise, C. (2005). Force and function in the acquisition of the preposition in. In L. Carlson \& E. van der Zee (Eds.), Functional features in language and space : insights from perception, categorization, and development. Oxford : Oxford University Press, 219-232.

Vandeloise, C. (2010). Genesis of spatial terms. In V. Evans \& P. Chilton (Eds.), Language, cognition and space : the state of the art and new directions. London : Equinox, 171-192.

\section{NOTES}

1. These terms correspond to trajector and landmark in Langacker's terminology and to figure and ground in Talmy's terminology.

2. In his analysis of the preposition at, Navarro-Ferrando (2002) attributes a central role to an encounter-schema with the landmark which bears some similarities with routines.

3. Kinetic prepositions like de ('from') or vers ('towards') do not trigger the principle of anticipation.

4. This point was not taken into account in the original formulation of the principle of anticipation (Vandeloise 1987).

5. See Dewell (2005) for an analysis compatible with this hypothesis, in which in is associated to the concept of entering.

6. A possible exception appears in L'enfant court à la toilette ('The child runs to the bathroom'). But, in this case, courir means aller en vitesse ('go quickly') and is not really a verb of manner of displacement.

7. I will come back on some exceptions in the next section.

8. Thomas (2005:157) also claims that "in directional under-constructions, a telic feature is present in the syntax exactly as in constructions with into/onto."

9. In these rules, container and support should be considered as the first members of the relation ships $\mathrm{C} / \mathrm{c}$ and $\mathrm{B} / \mathrm{b}$ (see section 4 ).

10. The preposition dans may be used if the name of the city is preceded by nouns like ville: L'Acropole est dans la ville d'Athènes 'The Acropolis is in the city of Athens'.

11. Names of countries in French are preceded by articles and au Canada is the contraction of 'à le Canada'.

12. This definition has been largely commented by the Neo-Platonicians (see Vandeloise, 2001 for a synthesis). 
13. Even though, as noticed by Husserl (1907), they never reveal all their boundaries at the same time.

14. This may account for the zero-dimensionality often attributed to the preposition at.

15. Function here is not limited to the specific function of an artifact. For example, the normal function of an umbrella is to protect from the rain. But an upside down umbrella with an apple inside (an example proposed by Feist to appear) has the function of a container, even though it is not its usual function. In cartoons, umbrellas can also have the function of walking sticks for husbands who get back home too late in the night.

\section{ABSTRACTS}

The spatial uses of the French prepositions à, dans and sur may be translated by either at, in, on or to, into, onto, depending on whether the landmark introduces the actual or the prospective position of the target. All static spatial French prepositions can bring in the actual position of the target as well as its prospective position. Instead of offering two meanings for these prepositions, I propose a general principle of anticipation that applies to the definition of these prepositions when the target is prospective. An adaptation of this principle applies to the spatial static English prepositions, with the exception of at, in and on. The prepositions into and onto are interpreted as compound words that elaborate the meaning of to. The prepositions dans and in mainly convey a relation of containment involving material entities. Such geographic entities as cities and countries, however, introduced by the French preposition of localization $\grave{a}$, are preceded by in in English. This may be explained because the functions of localization and containment share certain properties: containers are ideal landmarks and some geographic entities have welldefined boundaries in which a target may be included.

Les usages spatiaux des prépositions spatiales du français $\grave{a}$, dans et sur peuvent être traduits par at, in, on ou bien to, into et onto selon que le site introduit la position actuelle ou prospective de la cible. Toutes les prépositions spatiales du français peuvent dénoter la position actuelle de la cible aussi bien que sa position prospective. Plutôt que de postuler deux sens de ces prépositions, je propose un principe général d'anticipation qui s'applique à leur définition lorsque le site est prospectif. Une adaptation de ce principe s'applique à la définition des prépositions spatiales statiques de l'anglais, à l'exception de at, in et on. Les prépositions into et onto sont interprétées comme des mots composés qui élaborent le sens de to. Les prépositions dans et in véhiculent principalement une relation de contenance impliquant des entités matérielles. Néanmoins, des entités géographiques telles que villes ou pays, introduites par la préposition de localisation à en français, sont précédées de in en anglais. Ceci peut s'expliquer par le fait que les fonctions de localisation et de contenance partagent certaines propriétés : les contenants sont des sites idéaux et quelques entités géographiques possèdent des limites bien définies dans lesquelles une cible peut être incluse. 
INDEX

Mots-clés: prépositions spatiales, français, anglais, usages statiques et cinétiques, contrôle, localisation

Keywords: spatial prepositions, French, English, static and kinetic uses, control, localization

\section{AUTHOR}

\section{CLAUDE VANDELOISE}

Louisiana State University, Baton Rouge, LA, USA 